\title{
INFLUENCING OF SPATIAL MEMORY IN RATS BY DSP-4 AND MESCALINE
}

\author{
Marie Koupilová ${ }^{1}$, Josef Herink ${ }^{1}$, Otakar Krs ${ }^{2}$ \\ Purkyně Military Medical Academy, Hradec Králové: Department of Toxicology ${ }^{1}$; Charles University in Prague, Faculty \\ of Medicine in Hradec Králové: Department of Anatomy ${ }^{1}$
}

Summary: Behavioural effects of two experimental neurotoxins, mescaline and DSP-4 (N-(2-chloroethyl)-N-ethyl-2-bromobenzylamine), on retention of spatial orientation were studied in the $\mathrm{T}$ - maze. The stereotaxic administration of both neurotoxins into the selected brain structures was chosen to reveal this effect. The intensity and time course of the neurotoxic effect were dependent on the brain area administered. Nevertheless, the lengthening of the latencies in reaching the goal was generally more marked after mescaline in comparison with DSP-4.

Key words: DSP - 4; Learning; Mescaline; Stereotaxic administration; T - maze

\section{Introduction}

Selective destruction of relatively homogeneous neuronal populations by means of specific neurotoxins represents an important experimental tool for modelling various pathological conditions of the central nervous system. The neurotoxin DSP-4, N-(2-chloroethyl)-N-ethyl-2-bromobenzylamine hydrochloride, has a predilection for the noradrenergic terminals of the brainstem nucleus of the locus coeruleus. It readily passes the blood - brain barrier when administered systemically to rats and causes a rapid and long-lasting depletion of norepinephrine (NE) in the cerebral cortex, hippocampus, cerebellum and spinal cord $(4,6)$. Although the effect of systemic administration of DSP-4 was studied extensively enough $(5,7,9)$, a lack of information exists on the local „lesion“ strategy. That is why we studied retention of spatial orientation in the T-maze with food motivation in rats subjected to DSP-4 lesions of selected brain areas. Effects of DSP-4 and hallucinogen mescaline, administered in the same way, were compared. The action of both drugs tested are possibly mediated via their spontaneously formed cyclic aziridinium ion derivatives in the brain $(8,22)$.

\section{Materials and methods}

Fifty four adult male Wistar rats weighing 210 - 250 $\mathrm{g}$ were used at the beginning of experiments. The animals were adapted to the conditions of the laboratory vivarium for a period of 14 days. Out of the experimental sessions, the rats were kept in plexiglass cages with three animals in each. During the experiments with appetitive motivation in the T-maze the diet was decreased to 8 pellets for a rat per day, water was accessible ad libitum. One group always consisted of six animals.

The T-maze was composed of fine segments (each 12 $\mathrm{cm}$ wide, $30 \mathrm{~cm}$ long, $11 \mathrm{~cm}$ high) fitted on one to another. Both the starting and finishing parts were the same measuring $26 \times 26 \mathrm{~cm}$. The experimental conditions utilized the rats ability to find their way along a set of passages. The hungry animal had the task to make its way through the maze, without turning aside into various arms, until it reached the exit, where food awaited it in form of a few pellets.

The rats were trained in the T-maze once a day for 14 days. The longest time spent in the maze was 3 minutes. Those animals which did not reach the exit or took longer than permitted 3 minutes were discarded. Completing their training, the rats were divided into six experimental groups (both drugs administered into three selected brain structures separately) and three groups of control shame-operated rats administered only saline into the same brain structures to check up on effects of anaesthesia and surgery.

Throughout the actual sessions, the time latency taken to reach the target and the number of incorrect turns aside were counted.

Administration of drugs tested was performed by means of permanently introduced cannula. Animals were placed in a stereotaxic frame under sodium thiopental $(50 \mathrm{mg} / \mathrm{kg}$ Thiopental VUFB inj., intraperitoneally) anaesthesia. After incision and retraction of skin, connective tissue and muscle, trephine openings approximately $1 \mathrm{~mm}$ in diameter were placed onto the exposed skull unilaterally to the left with respect to the sagittal suture. The stereotaxic coordinates of the intracerebral cannulae were as follows: the ventriculus lateralis cerebri - $1.0 \mathrm{~mm}$ behind the bregma, $3.75 \mathrm{~mm}$ below the surface of the skull (V) and $1.6 \mathrm{~mm}$ laterally to the 
sagittal suture (L), the nucleus basalis of Meynert (nbM) $0.8 \mathrm{~mm}$ behind the bregma, $\mathrm{V}=8.0 \mathrm{~mm}, \mathrm{~L}=2.6 \mathrm{~mm}$, the nucleus septi medialis ( $\mathrm{nsm})-0.75 \mathrm{~mm}$ before the bregma, $\mathrm{V}=5.5 \mathrm{~mm}, \mathrm{~L}=0$. Recovery period between surgery and drug administration was 48 hours. DSP - 4 and mescaline were given in a dose of $0.1 \mathrm{mg}$ in a volume of $3 \mu 1$ of $0.9 \%$ saline.

Effect of mescaline was investigated 60 and 120 minutes after administration and further during 22 succesive days (one trial per day). Effect of DSP-4 was investigated 30 and 90 minutes after administration and then during 9 consecutive days (one trial per day).

At the end of this study, the experimental animals were given a lethal dose of sodium thiopenthal, brains were removed after tracing the cannula pathway with methylene blue for verification of targeted brain structures, frontal brain sections were processed by standard histological method for hematoxyline-eosine stained slides.

The statistical analyses were performed on a PC with the BMDP program P7D: analysis of variance (ANOVA), ttest with Bonfferoni's correction.

Tab. 1: Control and experimental groups, their characterization, number of animals in each group used, concentration of chemicals, site of their administration in the brain structures, and time schedule of examination

\begin{tabular}{|l|l|c|l|}
\hline \multicolumn{1}{|c|}{ Group } & \multicolumn{1}{c|}{ Drugs } & Structure & \multicolumn{1}{c|}{ Time of Examination } \\
\hline Control & $0,9 \%$ saline & v.c.l. & $30,60,90,120$ min., \\
\hline Experiment 1 & Mescaline & n.b.M. & $1,2,3,4,5,6,7,8$, \\
\hline Experiment 2 & DSP - 4 & n.s.m. & $9,10,14,15,16,19$, \\
\hline $\mathrm{n}=6$ & $0,1 \mathrm{mg}$ in 3 1 & & 21,22 days \\
\hline & $0,9 \%$ saline & & \\
\hline
\end{tabular}

\section{Results}

Mescaline lengthened time latency of finding the goal in the T-maze 60 and 120 minutes after its administration into the nbM and nsm. At the same time, the effect of intracerebroventricular administration of mescaline did not differ from the control group with saline only. After mescaline administration, the deterioration of spatial orientation was observed in all groups with structures tested on day 1 and day 2. However, decline in time latency outlasted for much longer time in the nbM group, and especially in the nsm group in comparison with rats given the mescaline into the lateral cerebral ventricle (Fig. 1). DSP-4 worsened the performance in the T-maze 30 and 90 minutes after its administration into the lateral cerebral ventricle, this effect lasted only 48 hours. Protraction of time latency was somewhat longer (until day 3) after administration of DSP-4 into the nbM. On the contrary, the lengthening of time latency was lesser in case of DSP-4 administration into the nsm (Fig. 2). Histological verification proved the right placement of the cannula tip into all targeted structures.

\section{Discussion}

We have previously demonstrated mescaline capability to impair spatial orientation and movement of experimental animals in an open field after systemic administration $(10,11)$. Attempting to obtain further information on possible sites of intervention of neurotoxins in the brain, we chose a local mode of administration into the selected brain structures in the present study.

The nbM and nsm represent the source of two principal cholinergic systems of the brain $(12,19)$. The role which septum plays for the hippocampus is similar to that of the nbM for the neocortex. At present, the key role of the nbM in the etiopathogenesis of senile dementia of Alzheimers type is recognized: it holds true particularly for early stages of this disease $(15,18)$.

Mescaline showed the most marked supressive effect on spatial behavior of experimental animals after administration into the nbM, and especially into the nsm. On the other hand, the administration into the lateral cerebral ventricle was less effective. These changes make us think of possible participation of monoaminergic neurotransmissíon in its mechanism of action. There are evidences that combined disruption of noradrenergic and cholinergic transmission may result in some cognitive disturbances $(1,2,15)$. At twophase effect of mescaline was also noted. It consisted of initial prolongation of examined time latency, followed by a certain shortening of it, which was followed by further period of latency prolongation. Similar pattern was observed by Davis and Hatoum (1987) in case of active evasive reaction. This effect could be explained by gradual interference of mescaline with more than only one neuronal mechanism. The first one could react „immediately“, i.e., in hours or maximally days after administration of single dose of drug. The second one is „delayed“ after latency of more than one week. We suppose that former „immediate“ mechanism is based on a direct action predominantly at the receptor level, whereas the "delayed" reaction probably reflects the actual destructive changes of the whole neuronal populations induced by the neurotoxic effect (8).

Also the results of experiments with DSP-4 make us think of participation of a central noradrenergic mechanism. Published data confirm participation of this system in some forms of learning and memory $(13,14,16,17,20)$. Depletion of norepinephrine after DSP-4 administration generally results in a decrease of searching activity, a decreased reaction to novelty, and increased latency of approach behaviour (4).

\section{Acknowledgements}

The technical help of Mrs. Helena Antlová and Mrs. Eva Reslová is gratefully acknowledged. Statistical analyses were performed by Mgr. Václav Bláha of the Biostatistic Unit of the Purkyně Military Medical Academy. This work was partly supported by grant No. 307/95/1537 from the Grant Agency of the Czech Republic. 


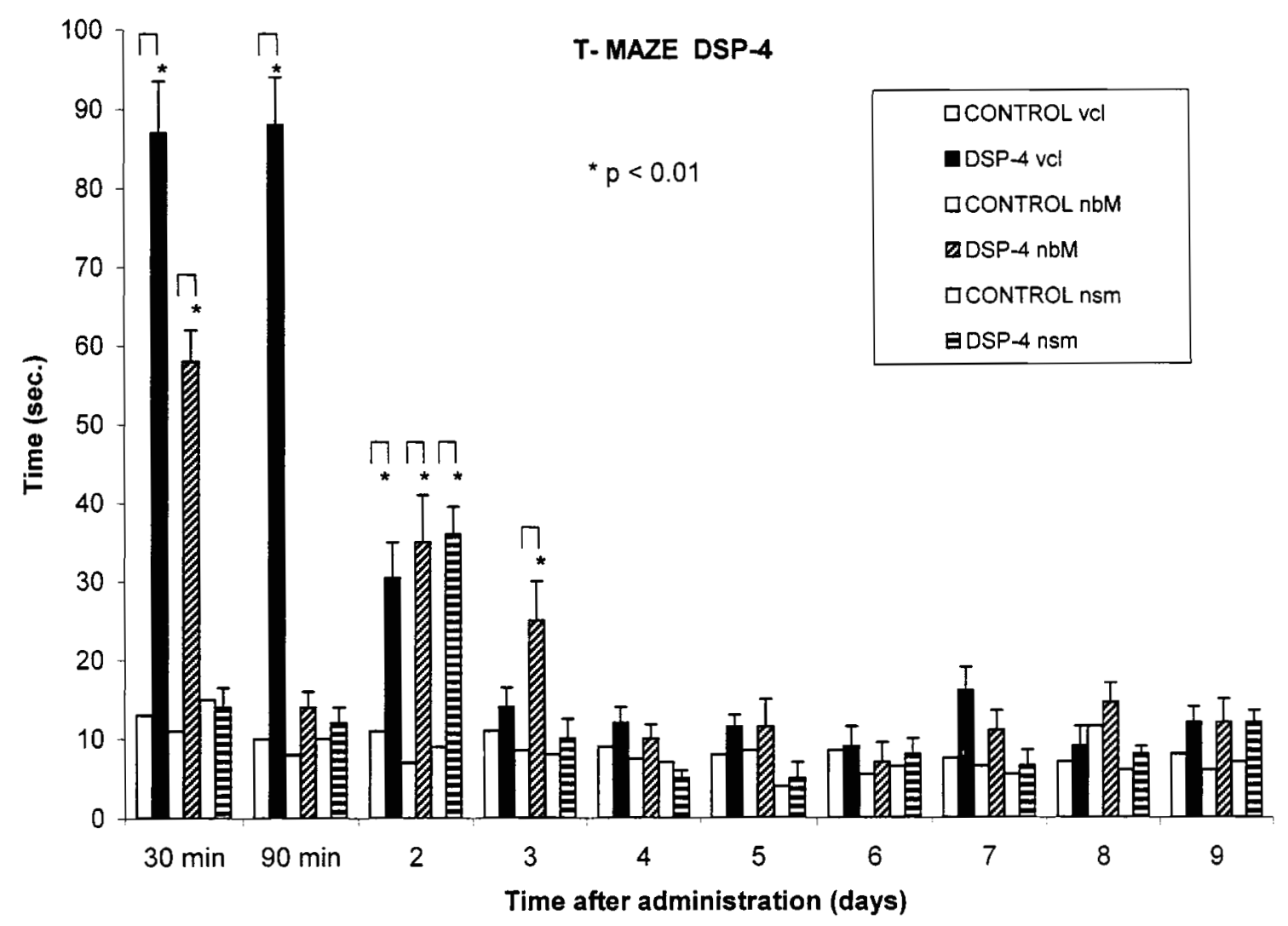

Fig. 1: Effect of mescaline in a dose of $0.1 \mathrm{mg}$ on spatial orientation of animals tested in the T-maze.

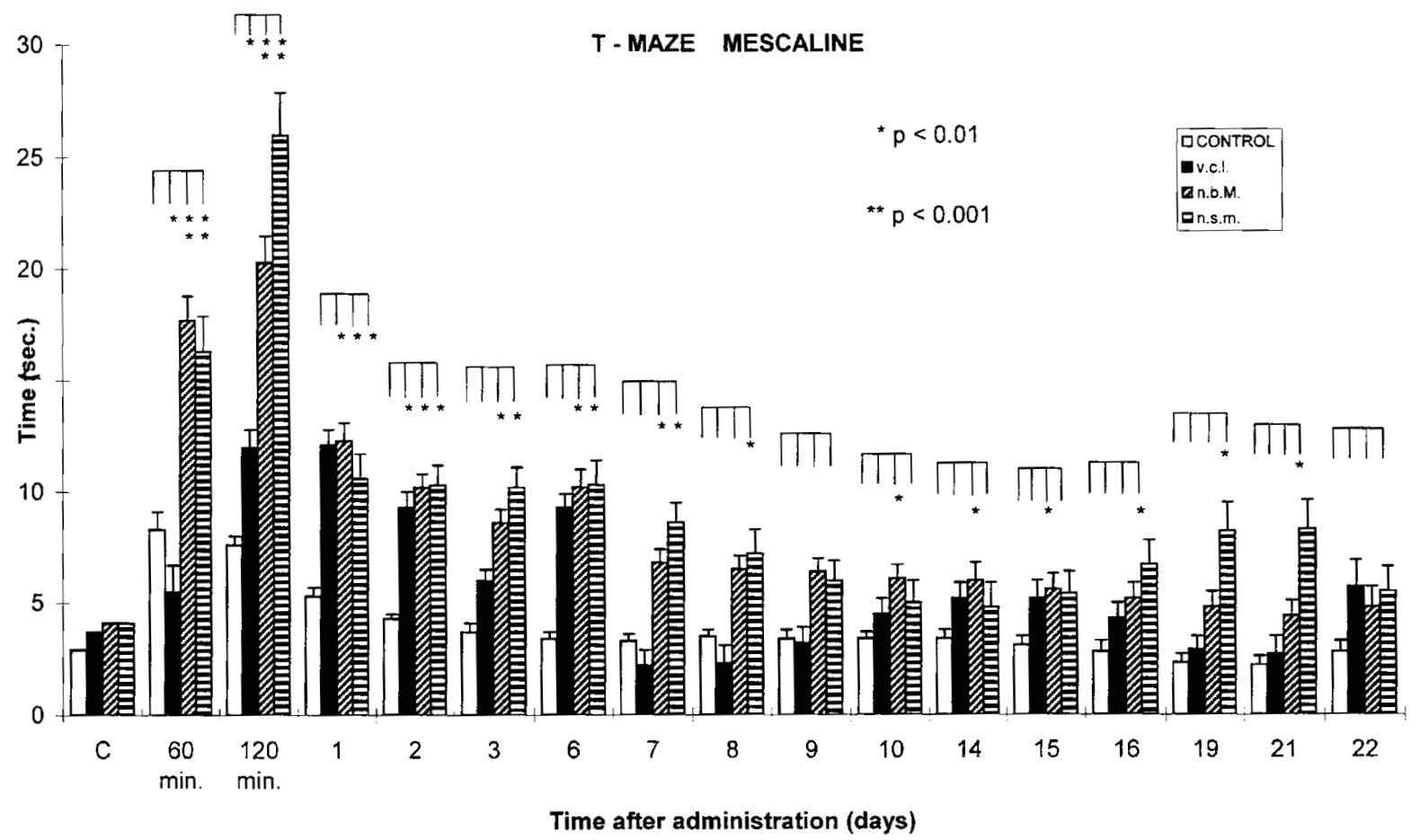

Fig. 2: Effect of DSP-4 in a dose of $0.1 \mathrm{mg}$ on spatial orientation of animals tested in the T-maze. 


\section{References}

1. Abe K, Horiuchi M, Yoshimura K. Potentiation by DSP-4 of EEG slowing and memory impairment in basal forebrainlesioned rats. Eur J Pharmacol 1997;321:149-55

2. Altman HL, Stone WS, rgen SO. Evidence for a possible functional interaction between serotonergic and cholinergic mechanisms in memory retrieval. Behav Neural Biol 1987;48:49-62

3. Davis WM and Hatoum HL. Comparison of stimulants and hallucinogens on shuttle avoidance. Gen Pharmac 1987;18;123-8.

4. Delini-Stula A, Mogilnicka E, Hunn C, Dooley DJ. Novelty-oriented behavior in the rat after selective damage of locus coeruleus projection by DSP-4, a new noradrenergic neurotoxin. Pharmacol Biochem Behav 1984;20:613-8.

5. Fritschy JM, Geffard M, Grzanna R. The response of noradrenergic axons to systemically administered DSP - 4 in the rat: an immunohistochemical study using antibodies to noradrenaline and dopamine-hydroxylase. J Chem Neuroanat 1990;3:309-21.

6. Gibson CJ. Inhibition of MAO B, but no MAO A, blocks DSP-4 toxicity on central NE neurons. European J Pharmacol 1987;141:135-8.

7. Grzanna R, Berger U, Fritschy JM, Geffard M. Acute action of DSP-4 on centra norepinephrine axons: biochemical and immunohistochemical evidence for differential effects. J Histochem Cytochem 1989;37:1435-42.

8. Herink J, Koupilová M, Krs O, Bajgar J, Patočka J. Modelling of some neuropathological states of the central nervous system by aziridine derivatives. Cesk Fyziol 1992;41:7-10.

9. Jaim-Etcheverry G and Zieher LH. DSP-4: a novel compound with neurotoxic effects on noradrenergic neurons of adult and developing rats. Brain Res 1980; 188:513-23

10. Koupilová $M$ and Herink J. Effects of mescaline and its derivative N-(3,4,5-trimethoxyphenylethyl)-aziridine on the spatial orientation of rats in a T-maze. Physiol Bohemoslov 1989;38:497-502.

11. Koupilová M, Herink J, Bajgar J. Effects of aziridine derivative N-(3,5-dimetho$\mathrm{xy}-4$-propoxyphenylethyl)-aziridine on learning and memory in laboratory rats. Homeostasis 1993;34:117-9.

12. Moran PM, Le Maitre MH, Philouze V, Reyman JM, Allain H, Leonard BE. Reversal of learning and memory impairment following lesion of the nucleus basalis magnocellularis (NMB) by concurrent noradrenergic depletion using DSP4 in the rat. Brain Res 1992;595:327-33.
13. Morley MJ, Shah K, Bradshaw CM, Szabadi E. DSP - 4 and Herrnsteins equation: further evidence for a role of noradrenaline in the maintenance of operant behaviour by positive reinforcement. Psychopharmacology 1988;96:551-6.

14. Ohno M, Yoshimatsu A, Kobayashi M, Watanabe S. Noradrenergic DSP-4 lesions aggravate impairment of working memory produced by hippocampal muscarinic blockade in rats. Pharmacol Biochem Behav 1997;57:257-61.

15. Santucci AC, Haroutunian V, Davis KL. Pharmacological alleviation of combined cholinenergic/noradrenergic lesion-induced memory deficits in rats. Clin Neuropharmacol 1991;14:1-8

16. Sirvi J, Riekkinen JrP, Valjaka A, Jolkkonen J, Riekkinen PJ. The effects of noradrenergic neurotoxin, DSP - 4, on the performance of young ang aged rats in spatial navigation task. Brain Res 1991;563:297-302.

17. Takasuna M, Iwasaki T. Active and passive avoidance learning in rats neonatally treated with intraventricular 6-hydroxydopamine. Behav Brain Res 1996;74:119 26.

Toledano-Gasca A. Hypothesis concerning the etiology of Alzheimers disease. Pharmacopsychiat. 1988;21:17-25.

18. Tuček S, Doležal V, Nedoma J. Cholinergic mechanisms in the brain. Activ Nerv Sup (Praha) 1986;28:42-3.

19. Zagrodska J, Wieczorek M, Romaniuk A. Social interactions in rats: behavioral and neurochemical alterations in DSP-4 - treated rats. Pharmacol Biochem Behav 1994;49:541-8

20. al-Zahrani SS, al-Ruwaitea AS, Ho MY, Bradshaw CM, Szabadi E. Destruction of central noradrenergic neurones with DSP-4 impairs the acquisition of temporal discrimination but does not affect memory for duration in a delayed conditional discrimination task. Psychopharmacology (Berl) 1997;130:166-73.

21. Zieher LM and Jaim-Etcheverry G. Neurotoxicity of N-(2-chloroethyl)-N-ethyl-2bromobenzylamine hydrochloride (DSP-4) on noradrenergic neurons is mimicked by its cyclic aziridinium derivative. Eur J Pharmacol 1980;65:249-52.

RNDr. Marie Koupilová, CSc., Purkyně Military Medical Academy, Dept. of Toxicology,

Šimkova 878, 50001 Hradec Králové, Czech Republic. e-mail: koupilova@pmfhk.cz 